\title{
O lugar da cidadania no capitalismo comunicativo
}

\author{
Where is the citizen in communicative capitalism?
}

Paola Madrid Sartoretto ${ }^{1}$

\begin{abstract}
Resumo: Este artigo discute como a participação cidadã na política através da ação comunicativa pode ser analisada a partir de uma apreciação crítica do conceito de capitalismo comunicativo. Não obstante sua contribuição para a análise crítica da participação política em ambientes digitais, o capitalismo comunicativo tem um caráter midiacêntrico e um viés etnocêntrico. Essas características limitam a aplicabilidade do conceito em análises das possibilidades de ação cidadã no contexto da comodificação da comunicação. Propõe-se, então, a cidadania comunicativa como um conceito que complementa as limitações do capitalismo comunicativo.
\end{abstract}

Palavras-chave: Capitalismo Comunicativo; Cidadania Comunicativa; Democracia; Participação.

\begin{abstract}
This article discusses how citizen participation in politics through communicative action can be analysed departing from a critical appreciation of the concept of communicative capitalism. Despite its contribution to a critical analysis of online political participation, communicative capitalism has a mediacentric character and an ethnocentric bias. These limitations make it less useful as an analytical tool to assess the possibilities for citizen action in the context of commoditized communication. Communicative citizenship is thus proposed as concept that addresses the analytical limitations of communicative capitalism.
\end{abstract}

Keywords: Communicative Capitalism; Communicative Citizenship; Democracy; Participation.

\section{Cidadania comunicativa na era da comunicação comodificada}

O rápido desenvolvimento e expansão global das tecnologias de informação e comunicação trouxe discussões sobre o potencial democrático e democratizante dessas tecnologias (COULDRY, 2012; BAKARDJIEVA, 2009; PAPACHARISSI, 2010; SHIRKY, 2008; SPARKS, 2000). A emergência de novas plataformas de publicação e disseminação de conteúdo virtual em rede, como Wikipedia, Wikileaks, Facebook, Twitter, Instagram, Whatsapp; bem como a crescente disseminação do acesso à internet e a dispositivos móveis de comunicação, foram encaradas inicialmente com otimismo (JENKINS et al., 2015; CASTELLS, 2013). Entretanto, nos últimos anos, esse

\footnotetext{
${ }^{1}$ Possui graduação em Comunicação Social pela Universidade Federal de Santa Maria (UFSM), mestrado em Mídia e Comunicação pela Universidade de Estocolmo e doutorado em Mídia e Comunicação pela Universidade de Karlstad, na Suécia. Atualmente leciona nas universidades de Estocolmo e Södertörn.
} 
otimismo tem dado lugar à problematização desse suposto potencial democrático das tecnologias de informação e comunicação. Tais debates são ancorados na ideia de que tanto a democracia quanto a cidadania possuem dimensões comunicativas, em outras palavras, a cidadania democrática não é apenas exercida através do voto e da participação em processos deliberativos, mas também através do engajamento em diálogos e debates na esfera pública materializada na mídia (HABERMAS, 1991; PERUZZO, 2014; COULDRY, 2012).

Uma linha de argumentação que surge desse debate considera o desenvolvimento das tecnologias de comunicação crucial para garantir a possibilidade de participação em debates públicos, e, consequentemente em outros processos políticos de curto e longo prazo. Entretanto, teme-se que, em razão do ethos mercadológico das plataformas digitais em geral, a simples produção e circulação de conteúdo e mensagens não são suficientes para garantir o tipo de comunicação intersubjetiva necessária para o exercício da cidadania (DEAN, 2008). Dean considera que as comunicações digitais dominadas por lógicas do mercado capitalista se constituem numa forma de capitalismo comunicativo no qual "valores tidos como centrais para a democracia se materializam nas tecnologias de comunicação em rede" (2009, p. 104, tradução minha). Recentemente, as empresas proprietárias de plataformas de comunicação, como Google e Facebook, têm sido inclusive acusadas de usar suas plataformas de maneira que cerceiam a liberdade de expressão de certos grupos, ao mesmo tempo que incitam discursos de ódio, além de exercerem influência indevida sobre processos eleitorais (ver, por exemplo, WYLIE, 2019). Revendo sua conceitualização, Dean (2020, p. 34) questiona quais seriam as repercussões do amálgama entre comunicação e capitalismo na maneira como nos comunicamos e nos entendemos como sujeitos. A autora reforça a ideia de que as mídias sociais acobertam a impotência política e fazem com que usuários se imaginem como participantes políticos ativos (DEAN, 2020, p. 35).

Essa avaliação crítica do papel da comunicação digital para a democracia chega depois do período de otimismo caracterizado pela glorificação do ativismo digital ${ }^{2}$. Em debates recentes se reconhece que não há evidências convincentes de que as mídias

\footnotetext{
${ }^{2}$ No livro The Revolution Will Not Be Televised, Joe Trippi (2005) argumenta que a internet poderia ter um grande impacto em campanhas políticas, incentivando o engajamento e participação individual, revitalizando assim esse processo democrático. Clay Shirky (2011) considera as mídias sociodigitais um elemento crucial para a organização de movimentos sociais e a ação política. Manuel Castells (2015) acredita que a internet é essencial para viabilizar a formação de movimentos sociais autônomos.
} 
digitais contribuam positivamente para a conscientização sobre questões de interesse público, ou mesmo para a participação em debates acerca de tais questões ${ }^{3}$. No contexto de um debate midiacêntrico acerca de um possível impacto positivo das redes sociodigitais em processos democráticos, o conceito de capitalismo comunicativo (DEAN, 2008, 2009, 2014, 2020) é útil para problematizar e explicar a relação entre interações comunicativas e processos políticos engendrados em ambientes digitais. Entretanto, o conceito se mostra insuficiente para analisar e explicar a agência da cidadania ou os limites da interação comunicativa para além do contexto das democracias liberais do Norte Global. Na conceitualização do capitalismo comunicativo, a participação toma a forma de expressão individual, excluindo da análise a comunicação coletiva como ação organizada. Propõe-se aqui o conceito de cidadania comunicativa (MATA, 2002) como uma alternativa para se entender as possibilidades e limitações da agência comunicativa e de processos coletivos de comunicação para o exercício da cidadania.

\section{Capitalismo comunicativo e os limites da participação}

Problematizando as oportunidades de participação cidadã e as ações políticas proporcionadas pelas tecnologias digitais de comunicação e informação, Dean introduz o conceito de capitalismo comunicativo para explicar o debate político nos Estados Unidos. Dean explica que:

Capitalismo comunicativo designa a forma do capitalismo tardio em que os valores tidos como centrais para a democracia tomam forma material nas tecnologias de comunicação em rede. Ideais de acesso, inclusão, discussão e participação se realizam nas e pelas expansões, intensificações e interconexões das telecomunicações globais. Mas em lugar de levar a uma distribuição mais equânime de recursos e influência, ao invés de possibilitar a emergência de uma variedade mais abundante de modos de vida e práticas de liberdade, o dilúvio de telas e espetáculos diminui qualquer oportunidade política para a maioria da população mundial (DEAN, 2008, p. 104, tradução minha).

$\mathrm{Na}$ prática, diferentes atores competem pela visibilidade e pela atenção de um público cada vez mais disperso e fragmentado, e as atividades políticas daqueles em

\footnotetext{
${ }^{3}$ Waisbord (2016).
} 
posição de poder acontecem em paralelo, independentemente da "política que circula como conteúdo" (DEAN, 2008, p. 104). Outra característica do capitalismo comunicativo, segundo Dean (2008), é que as mensagens se transformam em contribuições. Essa diferenciação é importante para compreender os limites da participação e da ação política nas redes sociodigitais. Enquanto a mensagem é o elemento material da comunicação, o que se faz comum (SODRÉ, 2015) entre atores comunicantes, pressupondo interação intersubjetiva, uma contribuição não requer esse nível de interação.

Dean argumenta que a questão em jogo não é se cidadãs e cidadãos possuem a habilidade, possibilidade e liberdade necessárias para participar do debate público, mas a ausência da interconexão entre o diálogo nas redes digitais e os processos da política nas instituições e na sociedade. De acordo com esse argumento, o principal objetivo da interação comunicativa na esfera pública é a influência política, seguindo a premissa da soberania cidadã, mas esse impacto nunca se concretiza porque, de acordo com Dean, existe uma diferenciação entre política e circulação de conteúdo (2005, p. 102). Isso acontece porque, no capitalismo comunicativo, diversas formas de interação comunicativa na internet operam como contribuições ao fluxo de mensagens. Essas contribuições não possuem valor democrático no sentido de influenciar mudanças sociais em geral ou deliberações políticas em particular. O papel das contribuições, na visão de Dean (2009), é gerar valor para as corporações que controlam as plataformas de comunicação digital. Nesse contexto, Couldry critica a possibilidade oferecida a cidadãos e cidadãs de resenhar serviços públicos no Reino Unido, argumentando que:

\footnotetext{
A legitimidade de um sistema político não pode ser resgatada através da introdução de pequenos elementos de "interatividade", ou mesmo pela transferência da decisão ao usuário ao mesmo tempo que se presta apenas atenção simbólica (por exemplo através de petições online ao Primeiro Ministro) à possibilidade de que o sistema político como um todo oferece uma prestação de contas adequada (COULDRY, 2010, p. 52, tradução minha).
}

De acordo com a lógica do capitalismo comunicativo, as formas de avaliações e comentários para serviços específicos cumprem na verdade a função de gerar valor e dar legitimidade às plataformas estatais e não oferecem a possibilidade de participação política. A participação política se entende aqui como ação coletiva capaz de influenciar 
mudanças institucionais a curto prazo e sociais a longo prazo. Essa participação se dá através do engajamento com atores sociais coletivos no escopo da sociedade civil, como, por exemplo, movimentos sociais ou mobilizações espontâneas. Esse tipo de ação não se resume à participação na política institucional, mas interage com as instituições do Estado. Na prática, a participação social coletiva pode ser uma forma de interlocução entre os atores sociais e as instituições do Estado e o governo. Um exemplo é a paralisação de trabalhadoras e trabalhadores de aplicativos de entrega de comida em julho de 2020 no Brasil. Através da mobilização para o "Breque dos apps", essas trabalhadoras e trabalhadores se mobilizaram nas ruas e nas redes sociais para dar visibilidade às suas demandas ao mesmo tempo que tentam iniciar uma interlocução coletiva com as instituições do Estado para garantir seus direitos em condições de precarização e redistribuição do trabalho comunicativo.

Ao adicionar o adjetivo "comunicativo" ao substantivo "capitalismo", Dean consegue articular um argumento eloquente sobre as limitações da interação comunicativa como ato político. No capitalismo comunicativo, a participação através da comunicação digital e das redes sociais não é apenas permitida, mas avidamente encorajada. Comentários e opiniões são publicados individualmente nas mais variadas formas. Entretanto, há aspectos que diferenciam esse tipo de participação das formas de participação cidadã apresentadas anteriormente. Em primeiro lugar, trata-se geralmente de uma participação individual enquanto consumidor de serviços e produtos dentro de um contexto neoliberal em que as relações são cada vez mais mediadas pelo mercado. Esse tipo de participação tem um ethos mais mercadológico do que político. Em segundo lugar, mesmo sendo errôneo afirmar que discussões políticas estão ausentes na interação em redes digitais, essas discussões dificilmente atingem seu objetivo, que é o de influenciar decisões e dinâmicas na política institucional, ou mesmo estimular alguma ação coletiva coordenada. Em consequência, a cidadania não é exercida através dessa forma de interação comunicativa porque o objetivo político da soberania popular ou cidadã, materializado numa relação simétrica entre cidadãs e representantes eleitos, bem como a politização das demandas, não são atingidos nessas interações. Assim como outras autoras (por exemplo, REGUILLO, 2017; ABREGO, BONA, REGUILLO, 2019; SASSEN, 2016), Dean (2014) considera as revoltas iniciadas na segunda década do século XXI, como os movimentos Occupy, o 15M na Espanha, os protestos no 
parque Gezi em Istambul e as Jornadas de Junho no Brasil, insurgências de classe sob a égide do capitalismo tardio. A autora rejeita o argumento de que tais mobilizações sejam pós-políticas ou movimentos locais e alerta para a nova aparência da luta de classes. Pode-se concluir, então, que o potencial de resistência e participação no capitalismo comunicativo se encontra fora das interfaces tecnológicas ao mesmo tempo que se utiliza delas de forma instrumental. A partir daí, argumenta-se que a comunicação é o processo constituinte da insurgência política contra o capitalismo neoliberal, configurando uma forma de cidadania insurgente (HOLSTON, 2013). Nas próximas seções se discute como a cidadania comunicativa pode conceitualizar esse tipo de ação política com base na apropriação consciente dos meios de comunicação e na reivindicação do protagonismo na elaboração de políticas de comunicação.

\section{Limitações epistemológicas do capitalismo comunicativo}

Conceitualmente, o capitalismo comunicativo tem limitações epistemológicas que diminuem sua capacidade de explicar dinâmicas de poder quando analisamos a relação entre comunicação, cidadania e democracia. O capitalismo comunicativo é um conceito explicitamente midiacêntrico, porque explica o caráter e impacto político (ou sua ausência) de interações comunicativas que ocorrem exclusivamente em ambientes digitais. Assim, esse conceito se torna inadequado para explicar e discutir o papel da comunicação como um processo social que se estende para além das mídias e ambientes digitais. Peruzzo (2014) explica que a comunicação através de canais tecnológicos é uma expressão de processos interativos entre indivíduos e grupos. Além do que, como lembra Silverstone (1999), as relações sociais transcendem e cercam as tecnologias, e, por isso, mesmo que as telas reproduzam a aparência de relações sociais, é preciso olhar para além delas para que possamos entender os processos de participação política na contemporaneidade.

Dean (2008, p. 103) reconhece que existe a possibilidade de se atingir resultados políticos através das redes digitais, mas tal possibilidade é dependente do contexto. Em outras palavras, o impacto político da interação midiática depende não apenas das potencialidades da tecnologia, mas também das condições político-sociais e das estruturas nas quais as tecnologias são utilizadas. Depara-se, então, com uma situação 
paradoxal em que mais indivíduos e grupos têm a possibilidade de expressão, mas, se utilizarem essas possibilidades para publicar e compartilhar mensagens, a capacidade de obter impacto político se dilui na cacofonia de mensagens. O grupo que Dean (2009) chama de "esquerda digitadora" (typing left) se engaja então numa crítica inoperante ao capitalismo (BOLTANSKI; CHIAPELLO, 2005) que tem o seu potencial de mudar as dinâmicas de poder existentes diminuído.

Ao mesmo tempo, não se pode ignorar o valor e o significado da voz, entendida como a capacidade humana de "apresentar a si próprio o seu lugar no mundo" (COULDRY, 2010, p. 1, tradução minha). Para Couldry, usar a voz é fazer o círculo completo de participação em condições democráticas, quando se consegue influenciar Estados e governos como interlocutores, ou contribuir para o entendimento mútuo entre diferentes grupos numa sociedade. A discussão que se faz necessária, portanto, é sobre quais condições favorecem uma crítica potencialmente significativa do capitalismo tardio.

Outra limitação conceitual do capitalismo comunicativo é seu viés etnocêntrico, o que diminui a capacidade de se usar o conceito para explicar realidades que não possuem características semelhantes às dos Estados Unidos ou da Europa Ocidental, também porque o conceito é delimitado pela ideia liberal da liberdade individual e liberdade da imprensa enquanto setor econômico. O capitalismo comunicativo perde assim suas propriedades analíticas quando escalonamos a discussão para incluir cidadania e participação em um contexto global e localizamos o debate em sociedades nas quais uma parcela significativa da população é excluída dos direitos associados à cidadania.

A dissociação entre a ação comunicativa em suas diferentes formas e as instituições que essa ação tem como objetivo modificar é uma característica de muitas sociedades contemporâneas. Essa dissociação tem relação com o papel do Estado neoliberal como provedor e gerenciador de serviços e não como instituição que garante direitos individuais e coletivos às cidadãs e aos cidadãos, o que torna suas demandas e opiniões menos relevantes. Assim, as redes sociodigitais oferecem possibilidades ilimitadas de expressão e facilitam certos tipos superficiais de participação e interação com órgãos do Estado. 
Se reconhecermos, como Dean (2009, 2020), Morozov (2012) e Couldry (2010), que as tecnologias falham em trazer soluções para problemas sociais e políticos, podemos chegar além da lógica do capitalismo comunicativo e começar a explorar as dinâmicas de comodificação da comunicação e seu impacto em processos democráticos. Ao fazer isso, é essencial adotar um posicionamento mais inclusivo que dê conta de experiências e fenômenos para além do eixo América do Norte - Europa Ocidental, o que vai resultar em um entendimento mais amplo das ameaças que o neoliberalismo representa para a democracia.

Assim, a questão a ser explorada aqui é: de que maneiras a comunicação enquanto processo social e coletivo pode aprofundar a cidadania e a participação política em contextos em que a comunicação é comodificada seguindo interesses comerciais e lógicas neoliberais?

\section{Cidadania comunicativa: uma visão ampliada da relação entre comunicação e participação política}

Buscando as raízes da conexão entre comunicação e cidadania, Mata (2006) observa que essa intersecção ganha atenção nos estudos de mídia e comunicação a partir da década de 1990. À luz dos processos de globalização, comercialização, individualização e neoliberalização, a ideia clássica de um coletivo de cidadãs e cidadãos engajadas e informadas, capazes de fazer escolhas racionais, e uma sociedade civil que se mobiliza objetivando o bem comum deu lugar a uma visão de indivíduos cínicos, passivos e autorreferenciados, engajados em processos contínuos de autoconstrução e autopromoção. Em paralelo, o constante desenvolvimento das tecnologias de comunicação e comodificação da informação trazem a cidadania para o centro das discussões. Mesmo existindo uma extensa literatura sobre cidadania nos campos da filosofia, sociologia e ciência política, o interesse sobre a intersecção entre comunicação e cidadania emerge com o reconhecimento de que cultura, identidade, informação e expressão são dimensões constitutivas da cidadania. Para que possam exercer direitos e deveres de cidadão em sua totalidade, indivíduos e coletivos precisam ser capazes de expressar sua identidade, receber e circular informação, além de produzir e reproduzir a cultura, ao mesmo tempo que participam de processos deliberativos 
(processos esses que não se limitam ao voto em eleições) que têm impacto em suas vidas. Essas ações se objetivam através de processos comunicativos muitas vezes materializados através dos meios de comunicação.

Nessa intersecção, Mata (2006) identificou uma tensão entre a posição social de público ou audiência e posição de cidadã e cidadão. No contexto do capitalismo comunicativo, essa tensão se materializa de uma maneira mais complexa, porque a condição de público implica não somente receber conteúdos, mas também produzir informação. Assim, o público se torna ativo, e essa atividade pode parecer e até configurar uma forma de agência (BAKARDJIEVA, 2009, 2012), mas isso não pode ofuscar o fato de que ao usar serviços e plataformas de corporações de tecnológica para a publicação e interação em rede, as audiências se apresentam publicamente como consumidoras e se comodificam no grande mercado de coleta, compilação e venda de dados. Mais do que consumidoras, indivíduos são usuárias de plataformas controladas por algumas das mais poderosas corporações da atualidade e se tornam um ativo para essas companhias através do conteúdo produzido e compartilhado e das informações armazenadas em perfis de redes sociais (McCHESNEY, 2013; MOROZOV, 2012; PAPACHARISSI, 2010).

A partir da perspectiva de grupos marginalizados que lutam para gerar mobilização e conscientizar o público sobre suas causas, as mídias digitais podem renovar as possibilidades disponíveis de autorrepresentação e disseminação de conteúdo (CASTELLS, 2011; DAHLGREN, 2009), formação de coletivos (BENNET, SEGERBERG, 2013; GERBAUDO, 2012), acesso à informação e também servir para a produção e reprodução da cultura. Esses processos trazem em seu bojo a necessidade de conceitos analíticos que expliquem a complexidade da posição dialética de cidadã-agente que se comunica para aparecer e participar em espaços de debate público e como público-commodity-consumidora.

Um ponto de partida é o reconhecimento dos modos pelos quais as dinâmicas do mercado invadem processos de sociabilidade. Martín-Barbero (1998) propõe que em face às tensões trazidas pelo desenvolvimento de tecnologias que configuram novos espaços públicos e formas renovadas de cidadania, é necessário observar e analisar a hegemonia comunicacional do mercado sobre a sociedade (1998, p. 11). Ele reconhece que é através da comunicação que culturas são inseridas no mercado mas também 
desconectadas dele enquanto sistema espaçotemporal. Aqui se nota um ponto em comum com o conceito de capitalismo comunicativo no sentido de que o domínio da lógica de mercado sobre a interação social é reconhecido e visibilizado. A diferença é que Martín-Barbero não limita a análise à internet, localizando as tensões comunicativas que emergem nas últimas décadas nas dimensões social e política, entendendo a comunicação como um processo, como o objeto do conflito, no lugar das instituições e tecnologias, como faz Dean. Para a autora (DEAN, 2020), a resistência às lógicas de exploração e exclusão vigentes no capitalismo comunicativo acontece essencialmente fora das tecnologias.

A hegemonia comunicacional do mercado limita a cidadania quando exclui certos modos de ação e invisibiliza certas lutas sociais. O espaço público da comunicação se torna opaco quando se omite de discutir a eficiência do mercado em organizá-lo. As políticas que regulamentam a atividade das empresas de comunicação, por exemplo, não se tornaram mais transparentes com o advento de novas tecnologias de comunicação, ao contrário, novas camadas de opacidade aparecem para ofuscar informações sobre como conteúdos são distribuídos e como dados pessoais são utilizados em plataformas digitais. Usuários de serviços de comunicação digital têm seus direitos limitados em termos de receber informação sobre empresas de tecnologia ou influenciar o modo como elas utilizam os dados gerados pelos usuários (ANDREJEVIC, 2007; TURKLE, 2015).

Temos assim um contexto em que o mercado detém controle hegemônico sobre todos os tipos de trocas simbólicas mediadas. Então, se entendemos a cidadania como a capacidade de ser sujeito em todos os campos de construção do poder (MATA, 2006) e se consideramos os meios de comunicação como arenas de disputa e negociação de poder, a incapacidade de ser o sujeito de suas próprias interações comunicativas mediadas pelas tecnologias configura a perda da cidadania. Como Mata explica, a prática da cidadania não se limita ao exercício de direitos e deveres, mas inclui também um modo específico de aparecer no espaço público onde cidadãs e cidadãos podem se constituir como sujeitos de demandas. Assim, nas sociedades contemporâneas midiatizadas, as mídias e redes de informação assumiram um papel central como arenas privilegiadas de interação social (COULDRY, 2010, 2012; PAIVA, 2005; SODRÉ, 2005). 
Ao questionar as possibilidades da ação cidadã em um espaço comunicacional dominado pelo mercado, Mata situa direitos e ação cidadã para além da mídia institucional. Para ela, a recusa ao consumo é uma ação individual realizada dentro dos limites do papel de consumidor. A ação cidadã, ao contrário, deve ser coletiva e transformadora. Nesse sentido, um termo mais adequado para descrever o exercício da cidadania em relação à comunicação seria direito à comunicação (PERUZZO, 2004). O direito à comunicação significa o reconhecimento de que direitos fundamentais intrinsecamente conectados à comunicação, como o direito à informação e à liberdade de expressão, não garantem a possibilidade da comunicação livre tampouco ajudam a evitar a concentração da propriedade dos meios de comunicação (BRITTOS; COLLAR, 2008). O reconhecimento desses direitos, inclusive no Norte Global, não preveniu a emergência do capitalismo comunicativo. Esse é o ponto em que o conceito de capitalismo comunicativo perde sua capacidade explanatória para o entendimento da intersecção entre cidadania e comunicação. A ação política cidadã através de interações comunicativas tem várias dimensões que não podem ser explicadas usando o capitalismo comunicativo como ferramenta de análise. Além disso, o direito à comunicação que torna possível a cidadania ativa está situado para além do capitalismo comunicativo como um sistema e como conceitualização da ação política na internet. A participação em redes sociais no capitalismo comunicativo é vista primordialmente como engajamento individual que não evolve para a formação de coletivos (a não ser formas efêmeras de agrupamento) e não permite uma discussão sobre as limitações e ameaças que a concentração da propriedade dos meios de comunicação representa para a democracia.

Enquanto o capitalismo comunicativo explica um contexto em que a ação comunicativa se desdobra na internet, analisando as forças estruturantes que fazem essa ação politicamente irrelevante (DEAN, 2009), a articulação entre cidadania e comunicação proposta por Mata (2006) revela os limites da cidadania dentro do capitalismo comunicativo ao mesmo tempo que estabelece mais explicitamente a conexão entre comunicação e democracia. Para Mata, é impossível conceitualizar e construir uma noção de cidadania sem o reconhecimento de que em sociedades midiatizadas, cidadãos e cidadãs assumem também a condição de públicos. Isso não significa apenas substituir o termo cidadã pelo termo público, mas reconhecer, 
identificar e analisar as tensões e problemas que emergem da intersecção entre as condições de cidadã e público - na mídia e da mídia. É a partir dessa perspectiva que a noção de cidadania comunicativa surge como o "reconhecimento da capacidade de ser sujeito de direitos e demandas na arena da comunicação pública e o exercício desse direito" (MATA, 2006, p. 13, tradução minha). A emergência da dimensão cidadã no campo da comunicação tem um caráter político, segundo Mata $(2002,2006)$, porque nos permite revelar até que ponto a apropriação de recursos pelo Estado e pelo mercado limita o exercício dos direitos que configuram a democracia.

Uma visão normativa da democracia liberal como um sistema político que provê oportunidades iguais às cidadãs e aos cidadãos como sujeitos de direito enquanto cria as condições para a formação cidadã se opõe à maneira como Dean (2009) entende as democracias liberais. Dean argumenta que as democracias liberais privilegiam os ricos ao estender e proteger o capitalismo neoliberal, o que se pode considerar os efeitos empíricos da noção liberal de democracia em que o Estado tem o papel de garantir liberdades individuais exercidas através de escolhas racionais, como o voto e a compra. Entretanto, nas democracias liberais, cidadãs e cidadãos nascem e não são formadas através da ação política. O capitalismo comunicativo é, então, o resultado da visão política liberal aplicada à comunicação e mídia em que o papel do Estado se limita a proteger a liberdade individual à expressão de opiniões e identidades. Nesse contexto, os direitos que Mata (2002) relaciona à comunicação não podem existir dentro do escopo de um Estado neoliberal, ou da democracia liberal em geral, porque a formação do sujeito da comunicação nesses contextos é medida pelo direito individual de ser parte de um público, pela capacidade individual de circular mensagens e pela liberdade para constituir empresas que ofereçam tais serviços. Em comparação, a cidadania comunicativa requer o reconhecimento da dupla condição de público-cidadã, possibilitando assim a ação cidadã para além do comportamento consumidor nos espaços públicos constituídos pela mídia.

Nos últimos anos, a pesquisa em comunicação na América Latina tem se utilizado do conceito de cidadania comunicativa para entender como grupos sociais marginalizados se apropriam das tecnologias e como a ação política é engendrada em processos comunicacionais que transcendem a tecnologia. Cogo (2012, p. 62) conclui que "práticas midiáticas, ainda que fragmentadas, colaboram para a criação de espaços 
de ação transnacional de mobilização e articulação da diáspora migratória latino-americana dispersa globalmente". Almeida, Guindani e Morigi (2010) argumentam que a rádio comunitária pode se tornar um catalisador da ação comunicativa em torno da cidadania, na qual se forjam "novas formas de sociabilidade e produção cultural" (p. 15). Caprino (2016) sublinha o papel da educação midiática para o reconhecimento e exercício da cidadania comunicativa com vistas a alcançar a cidadania comunicativa ideal (MATA, 2006), que é o protagonismo comunicacional enquanto sujeito da comunicação individual e coletiva. Saggin e Bonin (2017, p. 107) identificam o âmbito da comunicação e suas tecnologias como importantes vetores de transformação da cultura política, também alertando para a importância da educação midiática em suas abordagens não instrumentais para que indivíduos se construam como sujeitos da comunicação. Cerbino e Belotti (2016) sugerem que os meios de comunicação populares, alternativos e comunitários se configuram em importantes pontos nodais em redes transnacionais que promovem o reconhecimento e exercício da cidadania comunicativa. Pode-se afirmar que existe, na América Latina, uma clara linha de pesquisa que pretende entender e conceitualizar a comunicação midiática enquanto ação política ancorada em processos sociais. Os trabalhos citados são exemplos de uma análise não instrumental dos usos das tecnologias. Tomados em conjunto, eles contribuem para que se entenda a mobilização política no contexto do capitalismo tardio, sem se limitar aos conteúdos aparentes nas redes sociodigitais.

Nota-se que uma parcela significativa dos estudos recentes que operacionalizam o conceito de cidadania comunicativa analisa a apropriação de meios de comunicação por grupos marginalizados. Nos casos acima, os meios de comunicação enquanto tecnologias e artefatos (rádio, audiovisual, mídias digitais) não são o centro da ação mas ferramentas para serem usadas no processo de conscientização, formação de coletivos e reivindicação de direitos. A simples utilização de uma tecnologia para a expressão não é considerada participação ou ação política, como acontece com a participação em redes sociodigitais, pois há um processo sócio-pedagógico que antecede o uso das tecnologias.

Assim, não obstante a relevância do conceito de capitalismo comunicativo, o reconhecimento dos limites da ação cidadã através da comunicação em democracias neoliberais não avança para análise do conflito de interesses entre as demandas cidadãs 
e a comodificação da comunicação. Nesse sentido, a conceitualização da cidadania comunicativa, que reconhece cidadãs e cidadãos como sujeitos de demandas através da comunicação e no campo da comunicação, relocaliza o foco da análise da mídia como uma realidade material para a comunicação como um processo social.

$\mathrm{O}$ entendimento da cidadania como uma condição em formação contínua e exercida através da comunicação nos permite, então, analisar: a) a condição dialética público-cidadão em relação à estrutura político-econômica dos meios de comunicação em escalas variadas e b) os limites e potencialidades das iniciativas de comunicação comunitária e cidadã em relação aos seus resultados internos e externos.

\section{Conclusão}

A conceitualização do capitalismo comunicativo (DEAN, 2008, 2009, 2014, 2020) traz uma importante contribuição para a análise crítica da comodificação da comunicação e as limitações que essa comodificação impõe à participação política cidadã. Entretanto, o conceito apresenta limitações que afetam sua utilidade como ferramenta analítica para questionar e discutir a cidadania como performance comunicativa.

Para entender a relação entre democracia, cidadania e comunicação num contexto de globalização neoliberal é necessário incluir áreas geopolíticas onde a democracia liberal não se desenvolveu plenamente e deslocar o foco das tecnologias de comunicação para a comunicação como processo social em que a tecnologia está presente. Indo além da crítica às discussões políticas em redes sociodigitais como um fluxo comunicacional que contribui mais para o sucesso das plataformas digitais em que elas acontecem do que para mudanças sociais, é preciso explorar e discutir a interseção entre comunicação e diferentes formas de participação política. Para tanto devemos ir além da análise e crítica da comunicação através de plataformas sociodigitais e abordar a distribuição de poder, reconhecendo os interesses conflitantes que estruturam processos comunicativos.

A conceitualização da cidadania comunicativa pode, assim, ser utilizada teoricamente como uma perspectiva para entender as múltiplas dimensões nas quais indivíduos podem participar como cidadãs e cidadãos em interações comunicativas e 
também para identificar dinâmicas e estruturas que limitam e cerceiam o direito à comunicação. O exercício da cidadania comunicativa vai além da participação individual através da mídia e inclui a relação entre instituições de mídia e cidadãs e cidadãos e suas interações comunicativas e também as interações comunicativas interpessoais. Dessa maneira, a crítica à comodificação dos públicos (como usuárias e consumidoras), do conteúdo e da participação articulada por Dean pode ser ampliada e incluir a análise de como a cidadania pode ser plenamente construída e exercida em um contexto de comodificação da comunicação.

\section{Referências}

ABREGO, Victor Hugo; BONA, Yann; REGUILLO, Rossana. Resistencias en red: Tecnopolítica y violencias. Designis, n. 30, p. 23-44, 2019.

ALMEIDA, Cristóvão Domingos de; GUINDANI, Joel Felipe; MORIGI, Valdir Jose. A prática de cidadania comunicativa na experiência de rádio comunitária. Anais Compós, p. 1-17, 2010.

ANDREJEVIC, Mark. iSpy: Surveillance and power in the interactive era. Lawrence:

University Press of Kansas, 2007. 326p.

BAKARDJIEVA, Maria. Subactivism: Lifeworld and Politics in the Age of the Internet. The Information Society, v. 25, n. 2, p. 91-104, jul.-dec. 2009.

BAKARDJIEVA, Maria. Reconfiguring the mediapolis: New media and civic agency. New Media \& Society, v. 14, n. 1, p. 63-79, jan.-jun. 2012.

BENNETT, W. Lance; SEGERBERG, Alexandra. The logic of connective action: Digital media and the personalization of contentious politics. Cambridge: Cambridge University Press, 2013. 256p.

BOLTANSKI, Luc; CHIAPELLO, Eve. The new spirit of capitalism. International Journal of Politics, Culture, and Society, v. 18, n. 3-4, p. 161-188, jun. 2005.

BRITTOS, Valério Cruz; COLLAR, Marcelo Schimitz. Direito à comunicação e democratização no Brasil. In: SARAIVA, Enrique; MARTINS, Paulo Emílio Matos; PIERANTI, Octavio Penna (org.). Democracia e regulação dos meios de comunicação de massa. Rio de Janeiro: Editora FGV, 2008. p. 71-90.

CAPRINO, Mônica Pegurer. Educação midiática nas ONGs brasileiras: experiências para a cidadania comunicativa. Comunicação \& Sociedade, v. 38, n. 3, p. 245-269, 2016.

CARPENTIER, Nico. Media and participation: A site of ideological-democratic struggle. Bristol: Intellect Books, 2011. 408p.

CASTELLS, Manuel. The power of identity: The information age - Economy, society, and culture. New Jersey: John Wiley \& Sons, 2011. 461p. 
CASTELLS, Manuel. Communication power. Oxford: Oxford University Press, 2013. 618p.

CASTELLS, Manuel. Networks of outrage and hope: Social movements in the Internet age. New Jersey: John Wiley \& Sons, 2015. 338p.

CERBINO, Mauro; BELOTTI, Francesca. Medios comunitarios como ejercicio de ciudadanía comunicativa: experiencias desde Argentina y Ecuador. Comunicar, v. 24, n. 47, p. 49-56, 2016.

COGO, Denise. Cidadania comunicativa das migrações transnacionais: usos de mídias e mobilização social de latino-americanos. In: COGO, Denise; ElHAJII, Mohammed; HUERTAS, Amparo. Diásporas, migrações, tecnologias da comunicação e identidades transnacionais. InCom UAB: 2012, p. 43-66.

COULDRY, Nick. Media, society, world: Social theory and digital media practice. Polity, 2012. 324p.

COULDRY, Nick. Why voice matters: Culture and politics after neoliberalism. Newbury Park: Sage, 2010. 184p.

DAHLGREN, Peter. Media and political engagement. Cambridge: Cambridge University Press, 2009. 246p.

DEAN, Jodi. Communicative capitalism and class struggle. Spheres - Journal for Digital Cultures, n. 1, p. 1-16, 2014.

DEAN, Jodi. Communicative capitalism: Circulation and the foreclosure of politics. In: BOLER, Megan (ed.). Digital Media and Democracy - Tactics in Hard Times. Cambridge: MIT Press, 2008. p. 101-122.

DEAN, Jodi. Communicative capitalism: This is what democracy looks like. Journal of Communication and Languages, n. 51, 2020.

DEAN, Jodi. Democracy and other neoliberal fantasies: Communicative capitalism and left politics. Durham: Duke University Press, 2009. 232p.

FENTON, Natalie. The internet and radical politics. In: CURRAN, James; FENTON, Natalie; FREEDMAN, Des. Misunderstanding the Internet. London: Routledge, 2012. 234p.

GERBAUDO, Paolo. Tweets and the Streets: Social Media and Contemporary Activism. London: Pluto Press, 2012. 208p.

HABERMAS, Jürgen. The structural transformation of the public sphere: An inquiry into a category of bourgeois society. Cambridge: MIT Press, 1991. 301p.

HABERMAS, Jürgen. The theory of communicative action. Volume 2 - Lifeworld and system: A critique of functionalist reason. Boston: Beacon Press, 1987. 465p.

HINDMAN, Matthew. The myth of digital democracy. New Jersey: Princeton University Press, 2018. 181p. 
HOLSTON, James. Cidadania insurgente: disjunções da democracia e da modernidade no Brasil. São Paulo: Editora Companhia das Letras, 2013. 488p.

JENKINS, Henry et al. Participatory culture in a networked era: A conversation on youth, learning, commerce, and politics. New Jersey: John Wiley \& Sons, 2015. 160p.

MATA, María Cristina. Comunicación, ciudadanía y poder: pistas para pensar su articulación. Diálogos de la Comunicación, v. 64, p. 65-76, 2002.

MATA, María Cristina. Comunicación y ciudadanía: problemas teórico-políticos de su articulación. Revista Fronteiras estudos midiáticos, v. 8, n. 1, p. 5-15, jan.-apr., 2006.

MARTÍN-BARBERO, Jesús. De los medios a las mediaciones: comunicación, cultura y hegemonía. Convenio Andrés Bello, 1998. 351p.

McCHESNEY, Robert W. Digital disconnect: How capitalism is turning the Internet against democracy. New York: The New Press, 2013. 320p.

MOROZOV, Evgeny. The net delusion: The dark side of Internet freedom. New York: Public Affairs, 2012. 448p.

PAIVA, Raquel; BARBALHO, Alexandre. Mídia e política de minorias. In: PAIVA, Raquel; BARBALHO, Alexandre. Comunicação e cultura das minorias. Rio de Janeiro: Mauad, 2005. 220p.

PAPACHARISSI, Zizi. A private sphere: Democracy in a digital age. Cambridge: Polity, 2010. 210p.

PERUZZO, Cicilia Maria Krohling. Communication in social movements: A new perspective on human rights. In: ASKANIUS, Tina et al. (ed.). Reclaiming the Public Sphere. London: Palgrave Macmillan, 2014. p. 167-183.

PERUZZO, Cicilia Maria Krohling. Direito à comunicação comunitária, participação popular e cidadania. In: OLIVEIRA, Maria José (org.). Comunicação pública. Campinas: Alínea, 2004. p. 49-79.

REGUILLO, Rossana. Paisajes insurrectos: jóvenes, redes y revueltas en el otoño civilizatorio. Barcelona: Ned Ediciones, 2017. 210p

SAGGIN, Lívia; BONIN, Jiani Adriana. Perspectivas para pensar as inter-relações entre sujeitos comunicantes e mídias digitais na constituição de cidadania

comunicativa. Conexão-Comunicação e Cultura, v. 16, n. 32, p. 16-32, 2017.

SASSEN, Saskia. Expulsões: Brutalidade e Complexidade na Economia Global. São Paulo: Paz e Terra, 2016.336p

SASSEN, Saskia. The political power of social media: Technology, the public sphere, and political change. Foreign affairs, v. 90, n. 1. p. 28-41, feb. 2001.

SILVERSTONE, Roger. Why study the media?. Newbury Park: Sage, 1999. 176p.

SHIRKY, Clay. The political power of social media: Technology, the public sphere, and political change. Foreign affairs, 2011, 28-41. 
SHIRKY, Clay. Here comes everybody: The power of organizing without organizations. Penguin, 2008. 352p.

SODRÉ, Muniz. A ciência do comum: notas para o método educacional. Petrópolis: Editora Vozes, 2015. 328p.

SODRÉ, Muniz. Por um conceito de minoria. In: PAIVA, Raquel; BARBALHO, Alexandre. Comunicação e cultura das minorias. Rio de Janeiro: Mauad, 2005. 220p.

SPARKS, Colin. The Internet and the global public sphere. In: BENNET, W. Lance; ENTMAN, Rober M. (ed.). Mediated politics: Communication in the Future of Democracy. Cambridge: Cambridge University Press, 2000. p. 75-95.

TRIPPI, Joe. The revolution will not be televised: Democracy, the Internet, and the overthrow of everything. New York: Regan Books, 2005. 336p.

TURKLE, Sherry. Reclaiming conversation: The power of talk in a digital age. London: Penguin, 2015. 448p.

WAISBORD, Silvio. El desamor con las redes sociales. Notícias de la Semana, Buenos Aires, 22 out. 2016. Disponível em: http://noticias.perfil.com/2016/10/22/el-desamor-con-las-redes-sociales/. Acesso em: 1 nov. 2016.

WYLIE, Christopher. Mindf*ck: Inside Cambridge Analytica's plot to break the world. London: Profile Books, 2019. 270p. 